\title{
Angina with normal coronary arteriograms Value of coronary sinus lactate estimation in diagnosis and treatment
}

\author{
GRAHAM JACKSON, P. J. RICHARDSON, LYNNE ATKINSON, \\ PETER ARMSTRONG, AND SAMUEL ORAM
}

\author{
From the Cardiac and Radiology Departments, King's College Hospital, Denmark Hill, London
}

SUMMARY Thirty-five patients with chest pain of sufficient severity to warrant coronary arteriography 0 had normal coronary arteriograms. In each of them coronary sinus lactate was measured before and during atrial pacing. In 16 the lactate metabolism was normal as shown by a change between resting and $\mathcal{\odot}$ peak pacing arteriovenous lactate difference of less than $0.09 \mathrm{mmol} / 1(0.8 \mathrm{mg} / 100 \mathrm{ml})$. Nineteen patients $\frac{\nabla}{+}$ had abnormal lactate metabolism, the change being greater than $0.09 \mathrm{mmol} / 1(0.8 \mathrm{mg} / 100 \mathrm{ml})$. Sixteen $\frac{\Phi}{3}$ $(84 \%)$ of the group with abnormal lactate metabolism responded symptomatically to oral beta-blockade $\underset{\Phi}{\Phi}$ in contrast to only one patient in the normal group $(P<0.001)$. After 1 year all 16 patients with abnormal $\vec{\bullet}$ lactate metabolism who had responded to beta-blockade worsened when placebo was substituted. Fifteen of the 16 patients with normal lactate metabolism had become free of symptoms on no specific drug therapy; it is thus unlikely that their original pain was of cardiac origin.

By estimating the coronary sinus lactate, it is, therefore, possible to divide patients with chest pain and normal coronary arteriograms into two groups. Those with pain of non-cardiac origin have normal lactate metabolism, are unlikely to respond to beta-blockade, and improve spontaneously. The group with $\frac{\Phi}{\Omega}$ abnormal lactate metabolism have genuine angina, usually respond to beta-blockade, and deteriorate $\overrightarrow{\overrightarrow{0}}$ when treatment is discontinued. Further observation is required to determine the prognosis of the two 3 groups and to estimate the frequency of development of coronary artery disease.

Up to 10 per cent of patients with suspected angina pectoris have normal coronary arteriograms (Kemp et al., 1973). Even when coronary arteries are normal, abnormal electrocardiograms at rest or on exercise and abnormal myocardial lactate metabolism after atrial pacing suggest myocardial ischaemia (Boudoulas et al., 1974; Richardson et al., 1974).

We report here a series of 35 patients with chest pain who had normal coronary arteriograms. All had coronary sinus lactate estimations after atrial pacing to identify the development of anaerobic myocardial metabolism. Their response to treatment was also assessed.

\section{Patients and methods}

PATIENTS

Thirty-five patients, 16 men aged 26 to 58 years

Received for publication 5 September 1977 (mean 46 years) and 19 women aged 21 to 54 years (mean 44 years), were investigated. In each case we? considered that the severity of the patient's chest pain warranted invasive investigation and graded the

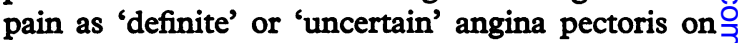
our interpretation of the symptoms. No patient had evidence of anaemia, thyroid disease, diabetes mellitus, valvar heart disease, hypertension, or $\frac{7}{8}$ autoimmune disease. Before the investigations beta-blocking drugs had been discontinued for $1 / \mathrm{N}$ week and digoxin for 2 weeks.

\section{ELECTROCARDIOGRAPHY}

A resting 12-lead electrocardiogram was recorded immediately before the radiotelemetric exercise electrocardiogram which was performed under standard conditions (Jackson et al., 1975). ST segment depression in lead V5 was measured before $\frac{0}{\circ}$ and after exercise. Ischaemia was considered $\stackrel{\mathbb{D}}{\mathbb{D}}$ present when there was ST segment depression of at $\frac{}{\Phi}$ least $1 \mathrm{~mm}$ for $0.08 \mathrm{~s}$ or more in at least 5 con-@ secutive beats. 
Table 1 Summary of results

\begin{tabular}{lllll}
\hline & & $\begin{array}{l}\text { Abnormal } \\
\text { lactate } \\
\text { metabolism } \\
(n=19)\end{array}$ & $\begin{array}{l}\text { Normal } \\
\text { lactate } \\
\text { metabolism } \\
(n=16)\end{array}$ & $P$ \\
\hline $\begin{array}{l}\text { Clinical } \\
\text { diagnosis }\end{array}$ & $\begin{array}{l}\text { 'Definite' } \\
\begin{array}{l}\text { Pacing } \\
\text { induced }\end{array}\end{array}$ & 16 & 3 & $<0.001$ \\
$\begin{array}{l}\text { angina } \\
\text { Abnormal } \\
\text { electro- } \\
\text { cardiogram }\end{array}$ & $\begin{aligned} \text { (Uncertain' } \\
\text { Resting }\end{aligned}$ & 17 & 13 & $<0.001$ \\
$\begin{array}{l}\text { Exercise } \\
\text { After pacing }\end{array}$ & 5 & 8 & 2 & $<0.02$ \\
\hline
\end{tabular}

NS, not significant; $n$, number of patients.

CORONARY SINUS LACTATE PACING STUDY This was performed as described in the preceding paper (Jackson et al., 1978).

\section{CORONARY ARTERIOGRAPHY}

This was performed as described in the preceding paper (Jackson et al., 1978).

\section{Results}

These are summarised in Table 1. Statistical analysis employed Student's t test and Fisher's exact test.

\section{CORONARY SINUS LACTATE}

Nineteen patients had a change in resting and peak pacing arteriovenous lactate difference greater than $0.09 \mathrm{mmol} / 1(0.8 \mathrm{mg} / 100 \mathrm{ml})$ which we consider is indicative of ischaemia (Jackson et al., 1978). Sixteen patients had normal myocardial lactate metabolism.

\section{CLINICAL DIAGNOSIS}

'Definite' angina was present in 19 patients (54\%), of whom 16 had abnormal lactate metabolism and 3 normal lactate metabolism $(P<0 \cdot 001)$.

\section{ELECTROCARDIOGRAPHY}

In 5 of the 19 patients with abnormal lactate metabolism the resting electrocardiogram was abnormal, but is was also abnormal in 2 of the 16 patients with normal lactate metabolism, a total incidence of 20 per cent. Of the 35 patients (30\%), 10 had an abnormal exercise electrocardiogram (Fig.), 8 coming from the abnormal lactate group. Of the 35 patients, 17 had abnormal electrocardiograms after pacing (50\%) (Parker et al., 1969), 13 of these were in the abnormal lactate group $(P<0.02)$. Pacing induced angina in a total of $25(71 \%)$ and 17 of these had abnormal lactate metabolism $(\mathrm{P}<0.02)$.

\section{ECHOCARDIOGRAPHY}

This was normal in all patients.

Table 2 Response to treatment

\begin{tabular}{llll}
\hline & $\begin{array}{l}\text { Abnormal } \\
\text { lactate } \\
\text { metabolism } \\
(n=19)\end{array}$ & $\begin{array}{l}\text { Normal } \\
\text { lactate } \\
\text { metabolism } \\
(n=16)\end{array}$ & $P$ \\
\hline $\begin{array}{l}\text { Relief of pain by } \\
\text { glyceryl trinitrate }\end{array}$ & 15 & 3 & $<0.001$ \\
$\begin{array}{l}\text { Improvement on treatment } \\
\text { with propranolol } \\
\text { pymptoms after stopping } \\
\text { propranolol }\end{array}$ & 16 & 1 & $<0.001$ \\
\hline
\end{tabular}

\section{RESPONSE TO TREATMENT}

All patients were treated with sublingual glyceryl trinitrate and oral propranolol. The dose of propranolol was increased until optimum betablockade was achieved, as defined by reduction of peak exercise heart rate (Jackson et al., 1975). Sixteen patients $(84 \%)$ within the abnormal lactate group responded to propranolol (Table 2) in contrast to only 1 patient with normal lactate metabolism $(P<0.001)$. All patients in the abnormal lactate group who responded to oral propranolol had an increase in the frequency of angina when placebo was substituted one year later, whereas 15 of the 16 patients with normal lactate metabolism had become pain free on no specific treatment. The withdrawal of beta-blockade was not associated with any rebound angina. Fourteen

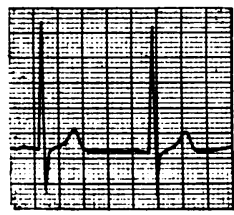

C

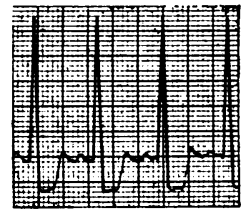

$P$

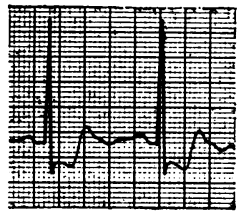

2

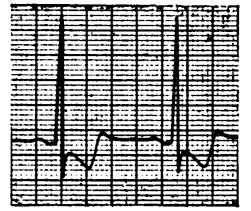

5

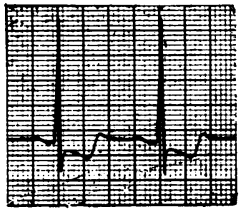

10

Fig. Depression of $S T$ segment by exercise in patient with normal coronary arteries. Control $(C)$, maximum $S T$ segment depression during exercise $(P)$, and 2,5 , and 10 minutes after exercise. 
patients $(74 \%)$ with abnormal lactate metabolism responded to glyceryl trinitrate while only $3(19 \%)$ with normal lactate metabolism did so $(P<0.001)$.

\section{Discussion}

Typical angina pectoris can occur in patients shown to have normal major coronary arteries on selective coronary arteriography (Kemp et al., 1973; Richardson et al., 1974). Previous studies have identified patients with normal coronary arteries with both abnormal electrocardiograms at rest or on exercise and abnormal lactate metabolism after atrial pacing (Boudoulas et al., 1974; Richardson et al., 1974). We have previously shown that patients with coronary artery disease have a change in resting and peak pacing arteriovenous lactate difference greater than $0.09 \mathrm{mmol} / \mathrm{l}(0.8 \mathrm{mg} / 100 \mathrm{ml})$ and we believe that this indicates the development of anaerobic metabolism (Jackson et al., 1978). By this definition, atrial pacing induced abnormal lactate metabolism in 19 patients.

It has also been shown in patients with coronary artery disease that myocardial lactate metabolism improves, and the time from atrial pacing to pain increases after glyceryl trinitrate (Chiong et al., 1972). We have recently shown that beta-blockers have a similar beneficial effect (Jackson et al., 1977). Of 19 patients with abnormal lactate metabolism, 15 responded to glyceryl trinitrate and 16 to propranolol. In contrast, of 16 patients with normal lactate metabolism only 1 responded to propranolol and 3 to glyceryl trinitrate. Measurement of coronary sinus lactate is thus the most reliable objective means of predicting response to either glyceryl trinitrate or propranolol. It was noteworthy that the patients with abnormal lactate metabolism all worsened when propranolol was withdrawn after 12 months of therapy, whereas all but 1 patient with normal lactate metabolism were free from pain on no specific treatment 12 months after investigation. As most of the patients with normal lactate metabolism had chest pain which had been labelled clinically 'uncertain' angina, it is likely that their pain was not of cardiac origin. We believe that there is now sufficient evidence for us to advocate the routine estimation of coronary sinus lactate before and during atrial pacing in patients with chest pain and normal coronary arteriograms, as there appear to be two distinct groups of patients who differ in their prognosis and response to treatment. While the outlook for patients with genuine angina and normal coronary arteriograms is good (Kemp et al., 1973), further follow-up is still required. It remains to be shown whether patients with angina and normal coronary arteriograms, but with abnormal lactate metabolism, are at risk of developing coronary artery disease.

\section{References}

Boudoulas, H., Cobb, T. C., Leighton, R. F., and Wilt, S. M. (1974). Myocardial lactate production in patients with angina-like chest pain and angiographically normal coronary $\infty$ arteries and left ventricle. American fournal of Cardiology, 34, 501-505.

Chiong, M. A., West, R. O., and Parker, J. O. (1972). Influence of nitroglycerin on myocardial metabolism and hemodynamics during angina induced by atrial pacing. Circulation, 45, 1044-1056.

Jackson, G., Atkinson, L., Clark, M., Crook, B., Armstrong, P., and Oram, S. (1978). Diagnosis of coronary artery disease by estimation of coronary sinus lactate. British Heart fournal, 40, 979-983.

Jackson, G., Atkinson, L., and Oram, S. (1975). Reassessment of failed beta-blocker treatment in angina pectoris by peak-exercise heart rate measurements. British Medical fournal, 3, 616-618.

Jackson, G., Atkinson, L., and Oram, S. (1977). Improvement of myocardial metabolism in coronary arterial disease by beta-blockade. British Heart fournal, 39, 829-833.

Kemp, H. G., Jr., Vokonas, P. S., Cohn, P. F., and Gorlin, R. (1973). The angina syndrome associated with normal coronary arteriograms. American fournal of Medicine, 54 735-742.

Parker, J. O., Chiong, M. A., West, R. O., and Case, R. C. (1969). Sequential alterations in myocardial lactate metabolism, S-T segments, and left ventricular function during angina induced by atrial pacing Circulation, 40, 113-131. Richardson, P. J., Livesley, B., Oram, S., Olsen, E. G. J., and Armstrong, P. (1974). Angina pectoris with normal coronary arteries; transvenous myocardial biopsy in diagnosis. Lancet, 2, 677-680.

Requests for reprints to Dr Samuel Oram, Cardiac Department, King's College Hospital, Denmark Hill, London SE5 9RS. 